Jiřı Čapek

Kamil Kolařik

Miroslav Neslušan

Zdeněk Pitrmuc

Libor Beránek

Karel Trojan

Jakub Němeček

Nikolaj Ganev

Jiři Kyncl

Petr Mikě̌

https://doi.org/10.21278/TOF.42401

ISSN 1333-1124

eISSN 1849-1391

\title{
SURFACE INTEGRITY AFTER TURNING A DUPLEX STAINLESS STEEL WITH RESPECT TO TOOL GEOMETRY
}

\begin{abstract}
Summary
This study deals with surface integrity expressed in terms of stress state as well as microstructure alterations after turning a duplex stainless steel. Residual stresses and the presence of strain-induced martensite are studied as functions of the rake angle. Residual stresses of surface and sub-surface layers were determined by the use of the X-ray diffraction and hole-drilling techniques. X-ray diffraction enables us to distinguish between residual stresses in each phase separately, which is not possible when the hole-drilling method is applied. Furthermore, alterations in the near surface region are also analysed by the use of the magnetic Barkhausen noise and metallographic observation.
\end{abstract}

Key words: $\quad$ duplex stainless steels, $X$-ray diffraction, residual stresses, strain-induced martensite, Barkhausen noise

\section{Introduction}

Duplex stainless steels consist of nearly equal amounts of austenite and ferrite phases. They have an attractive combination of very good corrosion and/or abrasion resistance and high mechanical strength. As regards the fatigue of duplex stainless steels, the cyclic deformation concentrates on the softer phase $[1,2]$. Which phase is softer depends on nitrogen content, heat treatment, etc. In the high-cycle fatigue regime, the austenite phase undergoes a higher amount of plastic deformation, and it contains tensile stresses and consequently yields easily [3]. On the other hand, the initial residual stresses relax rapidly during the low-cycle fatigue regime and both phases have been shown to deform more $[4,5]$.

Austenite contains a face centred cubic (fcc) lattice with a close-packing structure of atoms and the primary slip system $\{111\}<110>$. The number of slip systems is 12 , which is 
an amount sufficient for plastic deformation. By intersecting these dislocations, the so called stair-rod dislocations can form. For further moving the stair-rod dislocations, which have small stacking fault energy, it is necessary to have a large amount of energy for intersection or cross slip of these dislocations. Therefore, austenite steels are susceptible to work hardening, which causes mechanical modification and inhomogeneity on the machined surface. The second type of deformation of high alloyed austenite steels takes place via twins. On the other hand, the ferrite crystallizes in a body centred cubic lattice (bcc). The slip direction in bcc materials is always $\langle 111\rangle$. Since in the bcc lattice there is no close-packing structure of atoms, more slip planes appear during the deformation, mostly planes $\{110\}$ and $\{211\}$. Bcc materials generally have higher stacking fault energy. Therefore, lower energies of dislocations are needed to realize these transverse slips. Bcc materials are stronger due to a higher number of slip systems in the strain field of forest dislocations [6].

Components made of duplex stainless steels are very often produced using machining cycles. However, specific mechanical, thermal and other properties cause difficulties during machining. Duplex stainless steels have a relatively low thermal conductivity (approx. 16 $\mathrm{W} \cdot \mathrm{m}^{-1} \cdot \mathrm{K}^{-1}$ ) [7], which leads to insufficient heat distribution into chip and workpiece and excessive heat accumulation in the cutting zone. This heat generation can result in microstructural changes, local changes of chemical composition, surface discoloration or can induce undesirable tensile residual stresses (RSs). Krolczyk and Legutko [8] reported that after turning the surface of a duplex stainless steel is characterized by the preferential orientation of a periodically iterated surface structure. Machining cycles should be optimised with respect to energy consumption, tool wear or surface integrity. Such aspects as tool geometry or/and cutting conditions should be carefully considered to minimize the negative effect of cutting especially when components with high demands on their functionality are produced [9]. It should be considered that any changes of the microstructure as well as RSs initiated during production could affect to some extent the bulk properties as well as the near surface (and subsurface) regions [10-12]. Furthermore, the quality of components during production could randomly vary under constant conditions. That being so, unacceptable components could be employed in real applications, which in turn can result in early crack initiation and premature failures. Therefore, it would be beneficial to implement reliable techniques to monitor the surface state after the final phase of production.

The analysis of polycrystalline materials by applying X-ray diffraction (XRD) methods is suitable for gaining information about the state of RSs and microstructure of both surface and subsurface layers. Using the XRD method, RSs can be determined for both phases separately [11]. On the other hand, other methods, such as hole-drilling, determine the RS gradient from the total relieved deformation of the material after the disruption of the RS balance. Sometimes the gradient of RSs is a more important indicator of machined components than the surface RSs, i.e. the surface compressive RSs do not mean the compressive RSs in the subsurface layers [11]. For this reason, it is very important to investigate the RS gradient.

The strain-induced martensite transformation can be caused by a sufficiently high rate of plastic deformation of surface layers and also by thermal instability of austenite [12, 13]. Martensite is harder and more brittle in comparison with austenite, which in turn can negatively affect the functionality of components.

The Rietveld refinement method is based on a comparison of a measured and a calculated diffraction pattern, which could be used to describe many aspects of the material's structure (such as phase composition, crystallite sizes and microstrains). In order to compare the quality of the approximation, the weighted profile factor ( $R_{w p}$ factor) is commonly used. The main contributions to the calculated intensity are given in the relationship: 
Surface Integrity after Turning a Duplex

Stainless Steel with Respect to Tool Geometry
J. Čapek, K. Kolařík, M. Neslušan, Z. Pitrmuc,

L. Beránek, K. Trojan, J. Němeček, N. Ganev, J. Kyncl, P. Mikeš

$$
I_{i}^{\text {calc }}=S_{F} \sum_{j=1}^{N \text { phases }} \frac{f_{j}}{V_{j}} \sum_{k=1}^{N \text { peaks }} L_{k}\left|F_{k, j}\right|^{2} S_{j}\left(2 \Theta-2 \Theta_{k, j}\right) P_{k, j} A_{j}+b_{i},
$$

where $\frac{f_{j}}{V_{j}}, L_{k}, F_{k, j}, S_{j},\left(2 \Theta-2 \Theta_{k, j}\right), P_{k, j}, A_{j}, b_{i}$ represent phase quantities, Lorentz-Polarization factor, structure factor, crystallite size and microstrain, residual stresses (and cell parameters), texture, film thickness and background, respectively [14]. The width and shape of a diffraction peak contribute to the broadening arising from the sample. The broadening consists of microstrain broadening and crystallite size broadening. Both effects vary as a function of $2 \Theta$, but in different ways. This allows us to distinguish between them.

Quite a long inspection time, high cost equipment and demand for highly skilled staff could be found as disadvantages of the XRD technique. Furthermore, a destructive method has to be used for RS gradient investigation. For this reason, the magnetic Barkhausen noise (MBN) technique could be alternatively employed. This is a non-destructive technique based on irreversible and discontinuous Bloch Walls (BWs). BWs are pinned in their positions despite the external magnetic field of different direction. As soon as the magnetic field attains the critical threshold, abrupt motions of the BWs occur in the form of Barkhausen jumps. These jumps produce electromagnetic pulses, which can be easily detected on the free surface. The MBN technique is very fast and non-destructive. On the other hand, this technique can be applied only to ferromagnetic bodies. The MBN is sensitive to RSs as well as the microstructure. BWs interfere with lattice defects, whereas RSs affect mainly the BW alignment [15-17]. Therefore, the MBN is potentially a promising technique for monitoring the surface state of a duplex stainless steel.

It should be reported that the MBN technique has been already employed for the investigation of duplex stainless steels. Lindgren [18] applied the MBN technique during the fatigue test of 2507 duplex stainless steel. He found that the MBN had a linear relationship with the nominal stress after the fatigue testing. Normando [19] applied the MBN for analysing the sigma phase (Fe-Cr) in duplex stainless steels during heat treatment and welding. Mészáros [20] studied the microstructure of duplex stainless steels after different regimes of heat treatment by using the MBN. Lindgren [21] reported about the relationship between RSs and MBN in duplex stainless steels. It is worth mentioning that the MBN signal from a duplex stainless steel originates only from the ferrite phase since the austenite phase is not ferromagnetic.

The implementation of non-destructive techniques in real industrial applications requires carrying out a study in which non-destructive signals are correlated with the real surface integrity expressed in many terms and investigated through conventional destructive analyses. Consequently, this study investigates the influence of the rake angle on RSs, the microstructure and corresponding MBN signal.

\section{Experimental part}

The tested tube-shaped samples of 100/86 mm in diameter were made of AISI 2205 duplex stainless steel. The samples were annealed in an air laboratory furnace for 5 hours at $420^{\circ} \mathrm{C}$ in order to reduce bulk macroscopic RSs. The samples were turned with inserts made of cementite carbides of variable rake angles $\left(-6^{\circ} ;-2^{\circ} ;+7^{\circ}\right.$ and $\left.+12^{\circ}\right)$. Other conditions: tool holder $D C L N R / L$ with a lead angle of $95^{\circ}$ (negative rhombic inserts), tip radius $0.4 \mathrm{~mm}$, cutting speed $140 \mathrm{~m} / \mathrm{min}$, cutting depth $2 \mathrm{~mm}$ and feed $0.14 \mathrm{~mm}$ When machining each tube segment, a new cutting tool was always employed so as to eliminate the effect of tool wear. The feed direction was parallel to the axis of the sample (tube) $A$ and perpendicular to the tangential direction $T$. The tangential direction corresponds with the direction of the cutting speed. 
The $X$ 'Pert PRO MPD diffractometer was used to measure lattice deformations in the austenite and the ferrite phase using the $\mathrm{Mn} K \alpha$ and the $\mathrm{Cr} K \alpha$ radiation, respectively. The average effective penetration depth of the X-ray radiation was approx. $4 \mu \mathrm{m}$ and $6 \mu \mathrm{m}$ in the ferrite and the austenite phase, respectively. Diffraction angles $2 \theta^{h k l}$ were determined from the peaks of the diffraction lines $K \alpha_{1}$ of the planes $\{311\}$ and $\{211\}$ of austenite and ferrite, respectively. Diffraction lines $K \alpha_{1}$ were fitted by the Pearson VII function and the Rachinger's method was used for the separation of the diffraction lines $K \alpha_{1}$ and $K \alpha_{2}$. To determine RSs, the Winholtz \& Cohen method [22] and X-ray elastic constants $1 / 2 s_{2}=7.18$ $\mathrm{TPa}^{-1}, s_{1}=-1.2 \mathrm{TPa}^{-1}$ and $1 / 2 s_{2}=5.75 \mathrm{TPa}^{-1}, s_{1}=-1.25 \mathrm{TPa}^{-1}$ were used for the austenite and the ferrite phase, respectively. In order to analyse the stress gradients beneath the samples surface, layers of material were gradually removed by electro-chemical polishing in the centre of the sample.

The phase composition of the surface layers was investigated by using the X'Pert PRO $M P D$ diffractometer in the grazing incidence diffraction geometry (GID). The measurements were performed with two constant incidence angles of $1.5^{\circ}$ and $2.5^{\circ}$, which correspond to the effective penetration depth of 0.3 and $0.5 \mu \mathrm{m}$, respectively.

The hole-drilling method was performed by using a sintered carbide milling drill of $1.8 \mathrm{~mm}$ in diameter (holes depth $2 \mathrm{~mm}$ ). The detection of the released deformations was carried out by three rectangular tensometric rosettes. RSs were calculated by using macroscopic elastic constants: Young's modulus $200 \mathrm{GPa}$ and Poisson's ratio 0.3.

The MBN was measured by the use of the RollScan 350 apparatus and analysed by the uScan 500 software (sine shape, magnetizing voltage $7 \mathrm{~V}$, magnetizing frequency $125 \mathrm{~Hz}$, sensor type $S 1-18-12-01$, and MBN pulses in the range from 10 to $1000 \mathrm{kHz}$ ). MBN values were obtained by averaging ten MBN bursts (five magnetising cycles). The MBN refers to the rms (effective) value of the signal.

To obtain optical microscopy images, a radial cut of each sample was made. The electrolytic etching of the investigated surfaces was carried out with $10 \%$ oxalic acid. Images were obtained by inclined illumination with $250 \times$ magnification.

The Vickers microhardness was analysed by using the microhardness tester FutureTech FM 100 based on ČSN EN ISO 6507-1. The tip was loaded with $0.1 \mathrm{~kg}$.

\section{Results and discussion}

\subsection{Surface residual stresses}

Fig. 1 shows the influence of the rake angle on the surface macroscopic RSs $\sigma_{A}, \sigma_{T}$. These RSs were obtained by averaging three measurements on the same surface machined with a certain insert rake angle. Generally, the increasing rake angle reduces the cutting force as well as the temperature in the cutting zone. For this reason, it was expected that the amplitude of the surface RS should decrease along with an increase in the rake angle. However, Fig. 1 clearly shows that the RSs in the tangential direction decrease only in the case of the first two rake angles followed by a remarkable increase afterwards. On the other hand, the RSs in the axial direction remain less affected and the influence of the rake angle is only minor. Fig. 1 also shows that the amplitude of the RSs of the austenite phase is more than 2 times higher than the amplitude of the RSs of the ferrite phase (such a statement is valid for both directions).

The different ranges of RSs of the austenite and the ferrite phases result from the different yield strength ratio $R m / R p_{0.2}$. The yield strength ratio for austenite steel is approx. 2.5 , which is a typical value for the plastic phase. On the other hand, the ferrite steel yield strength ratio is less than 1.25 , which is a typical value for the elastic phase [23]. The different 
Surface Integrity after Turning a Duplex

Stainless Steel with Respect to Tool Geometry
J. Čapek, K. Kolařík, M. Neslušan, Z. Pitrmuc,

L. Beránek, K. Trojan, J. Němeček, N. Ganev, J. Kyncl, P. Mikeš

response of the phases to the exerted mechanical and thermal load results in different states of the RSs. Consequently, the processes associated with the plastic deformation (especially dislocation motion and dislocation density) are more developed in the austenite phase, which in turn produces higher RSs. Furthermore, it is possible to presume that the evolution of RSs along with the side rake angle is not the same in both phases because their mutual interference takes place during the plastic deformation at elevated temperatures, see Fig. 1.

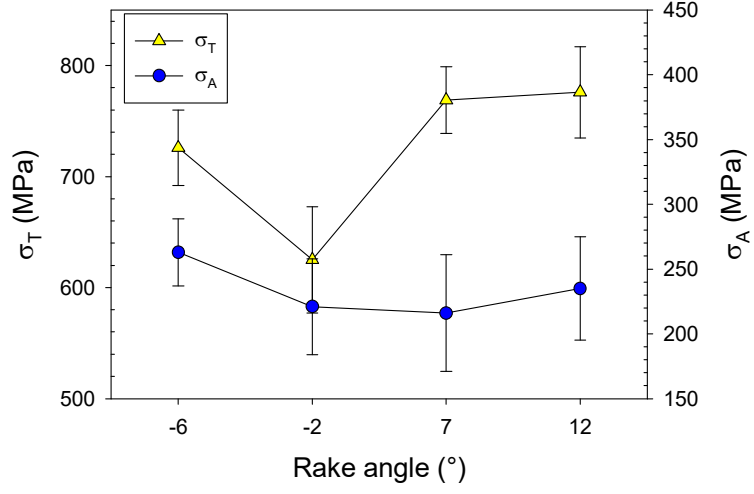

a) austenite phase

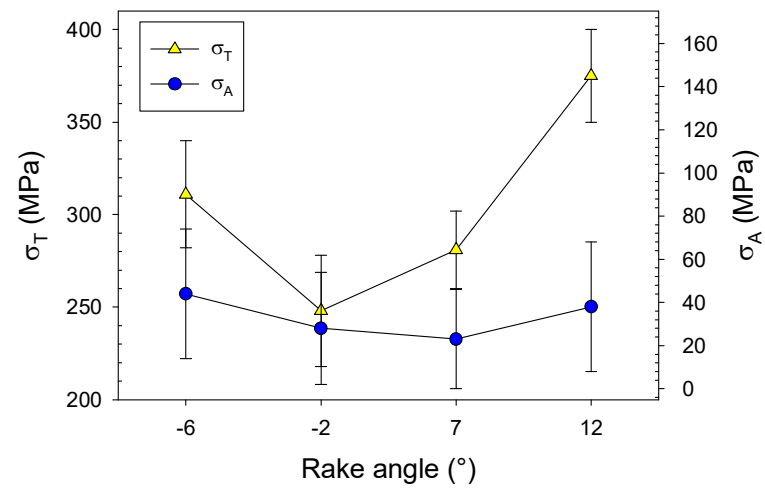

b) ferrite phase

Fig. 1 Axial and tangential surface RSs $\sigma_{A}, \sigma_{T}$ as functions of rake angle

\subsection{Residual stresses gradient}

Both phases exhibit a quite steep RS gradient when the near surface tensile RSs turn into compressive RSs in the deeper region, see Fig. 2. However, the ferrite RSs in the deeper layers (below $150 \mu \mathrm{m}$ ) remain compressive whereas the austenite RSs turn into tensile RSs. The influence of the rake angle on the RS profile is only minor and the $\sigma_{A}$ RSs are lower than the $\sigma_{T}$ RSs. Furthermore, the maximum of the compressive RSs is gently moved deeper beneath the free surface. Such behaviour was also reported by Dahlman [24].

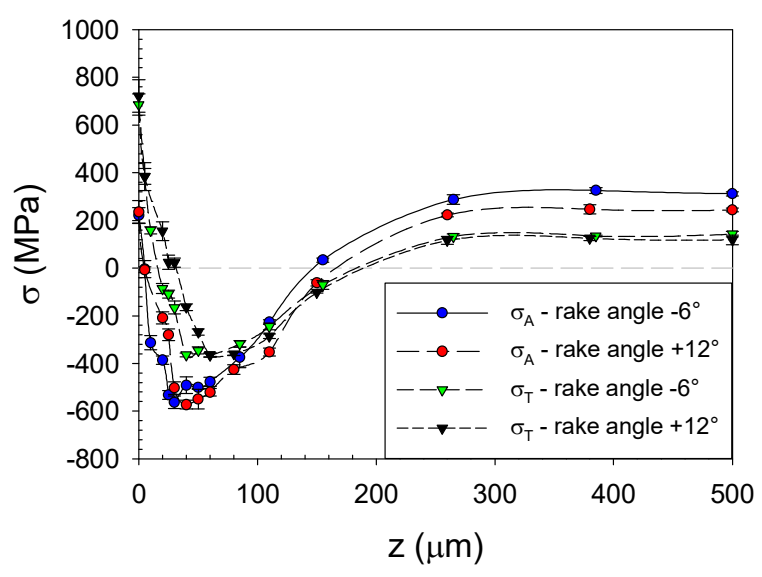

a) austenite phase

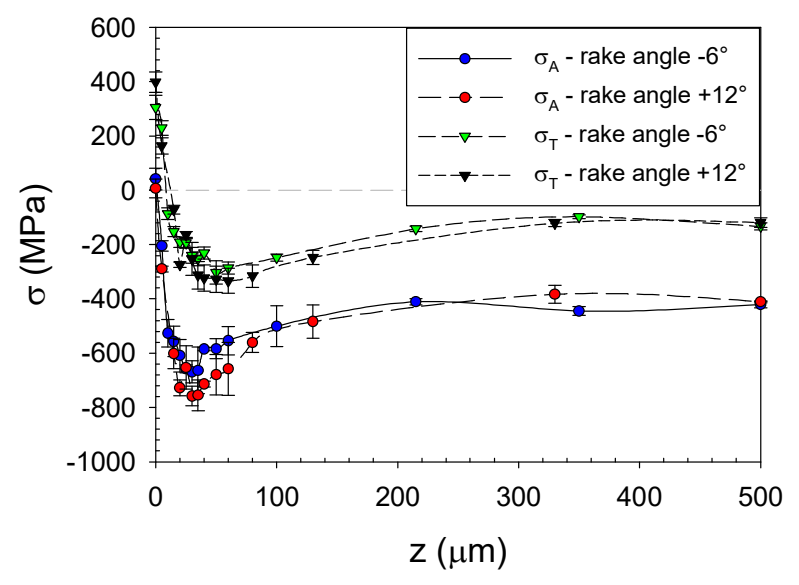

d) ferrite phase

Fig. 2 RSs gradients $\sigma_{A}, \sigma_{T}$ for rake angles $-6^{\circ}$ and $+12^{\circ}$

Fig. 3 and Fig. 4 depict a comparison of the analysed RSs depth profiles determined by the XRD and the hole-drilling method. The macroscopic RSs measured by the hole-drilling technique in deeper regions (approximately in the depth of $250 \mu \mathrm{m}$ and deeper) are close to zero. On the other hand, the XRD technique can distinguish between the RSs of both phases. In the case of a similar mass ratio of the ferrite and the austenite phase in the duplex stainless steel, the RSs of the bulk material can be approximately predicted by the value 
$\sigma_{\text {bulk }} \approx\left(\sigma_{\text {ferrite }}+\sigma_{\text {austenite }}\right) / 2$. In the tangential direction of both rake angles, a good match with the hole-drilling method can be seen. However, in the case of the axial direction, the sum of the RSs of both phases does not match the RSs from the hole-drilling method. This difference is most likely due to the texture of the material or the mass of the ferrite phase, which is not exactly $50 \%$. However, the hole-drilling method is based on the deformation of the measured material as a whole (therefore $\sigma_{\text {bulk }} \approx \sigma_{\text {hole-drill }} \approx 0$ [13]).

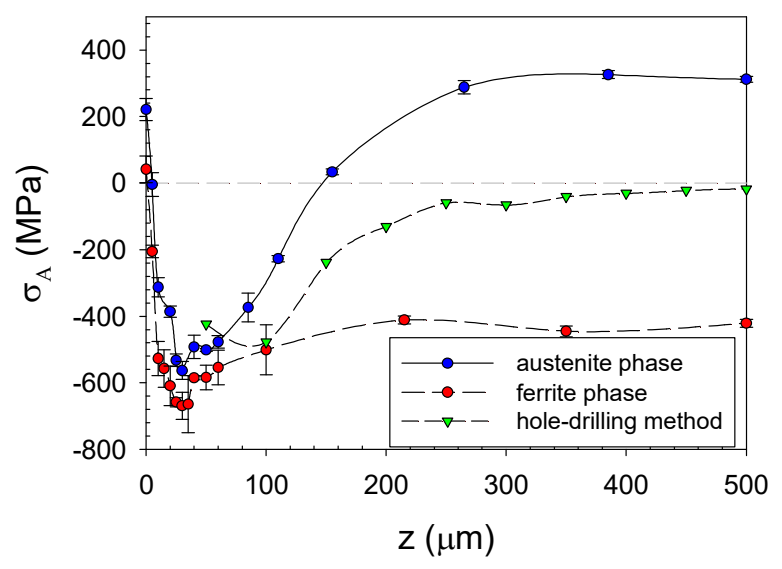

a) axial direction

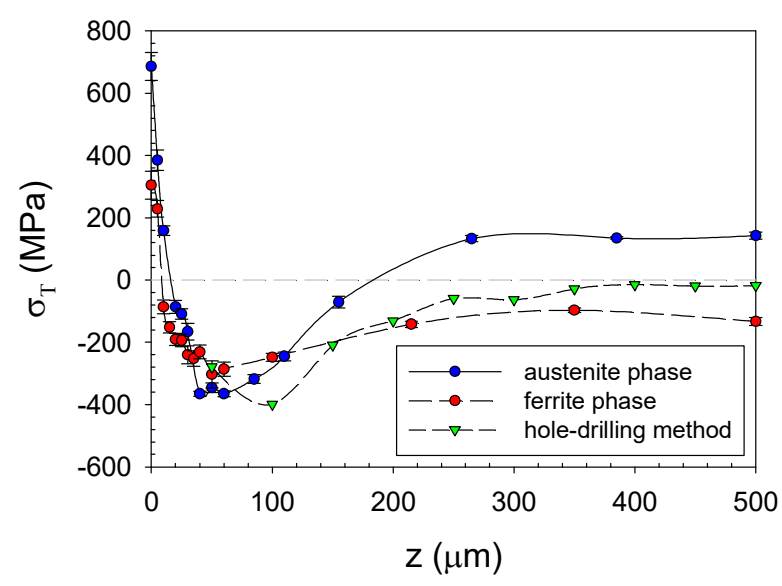

b) tangential direction

Fig. 3 Residual stress gradients $\sigma_{A}, \sigma_{T}$ at rake angle of $-6^{\circ}$

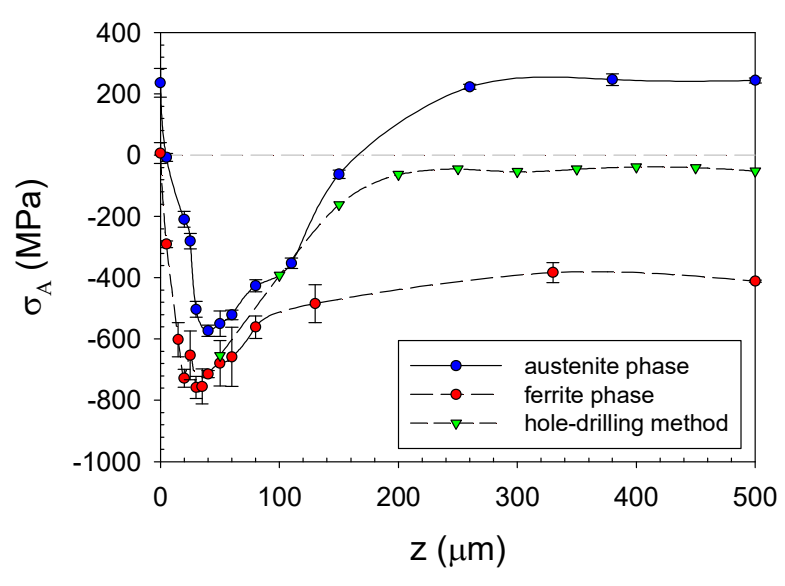

a) axial direction

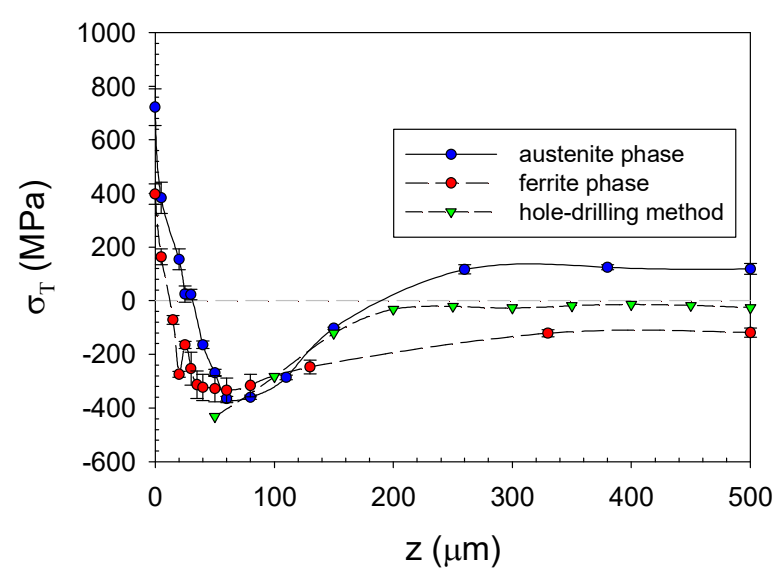

b) tangential direction

Fig. 4 Residual stress gradients $\sigma_{A}, \sigma_{T}$ at rake angle of $+12^{\circ}$

\subsection{Crystallite size, microdeformation and microhardness depth profiles}

A part of the undeformed layer in the cutting zone does not produce chips but goes under the cutting edge due to the cutting edge radius. The machined surface is exposed to severe plastic deformation at elevated temperatures. Such a process initiates remarkable changes not only considering RSs but also the microstructure expressed in many terms. Fig. 5 illustrates that the crystallite size $D$ (extracted from the XRD records) becomes much finer in the near surface region, increases rapidly in the subsurface layers and saturates early in the deeper layers. The saturated values correspond with the crystallite size of the bulk phases. Fig. 5 clearly shows that the bulk crystallite size of the austenite phase is approx. $70 \mathrm{~nm}$, whereas the ferrite phase crystallite size is approx. $90 \mathrm{~nm}$. Furthermore, the crystallite size on the free 
surface of the austenite is approx. $20 \mathrm{~nm}$ and $35 \mathrm{~nm}$ of the ferrite phase. The rake angle as well as the direction of measurement have nearly no influence on the measured $D$. Typical dislocation hardening of the austenite phase results in higher dislocation density (comparing to the ferrite phase), which in turn corresponds with the lower crystallite size $D$ of the austenite phase. This aspect also affects the calculated microdeformations as those illustrated in Fig. 6. The different degree of plastic deformation also remarkably contributes to the differences in microdeformation $e$. Both the rake angle and the direction of measurement have nearly no influence on the measured $e$. The depth profiles of $e$ and $D$ coincide with RS profiles and confirm that the intensity of the plastic deformation at elevated temperature is very high in the near surface region and rapidly decreases with an increase in the distance from the free surface.

Microhardness profiles, see Fig. 7, coincide with the profiles of $D$ and $e$ in which a steep increase (respective decrease) can be found within the $0.1 \mathrm{~mm}$ thin surface layer followed by saturation in deeper regions. Furthermore, the rake angle has no influence on the microhardness profile. However, the thickness of the altered near surface region in which more remarkable differences in microhardness are assumed is quite low and the applied technique is more sensitive to the changes in deeper subsurface regions.
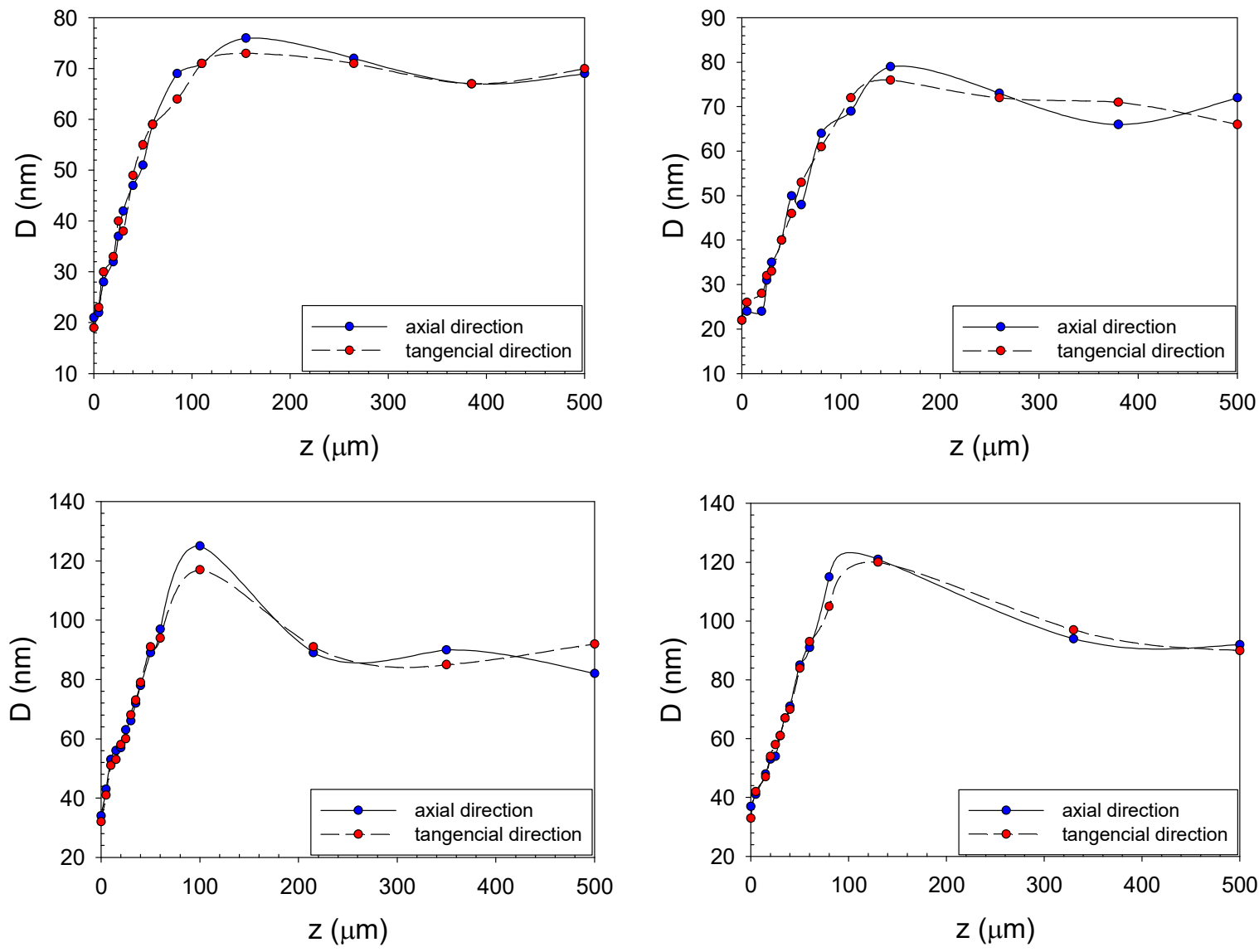

Fig. 5 Depth profiles of crystallite size $D$ of austenite (top) and ferrite (bottom) phase, rake angles of $-6^{\circ}$ (left) and $+12^{\circ}$ (right) 
J. Čapek, K. Kolařík, M. Neslušan, Z. Pitrmuc, L. Beránek, K. Trojan, J. Němeček, N. Ganev, J. Kyncl, P. Mikeš
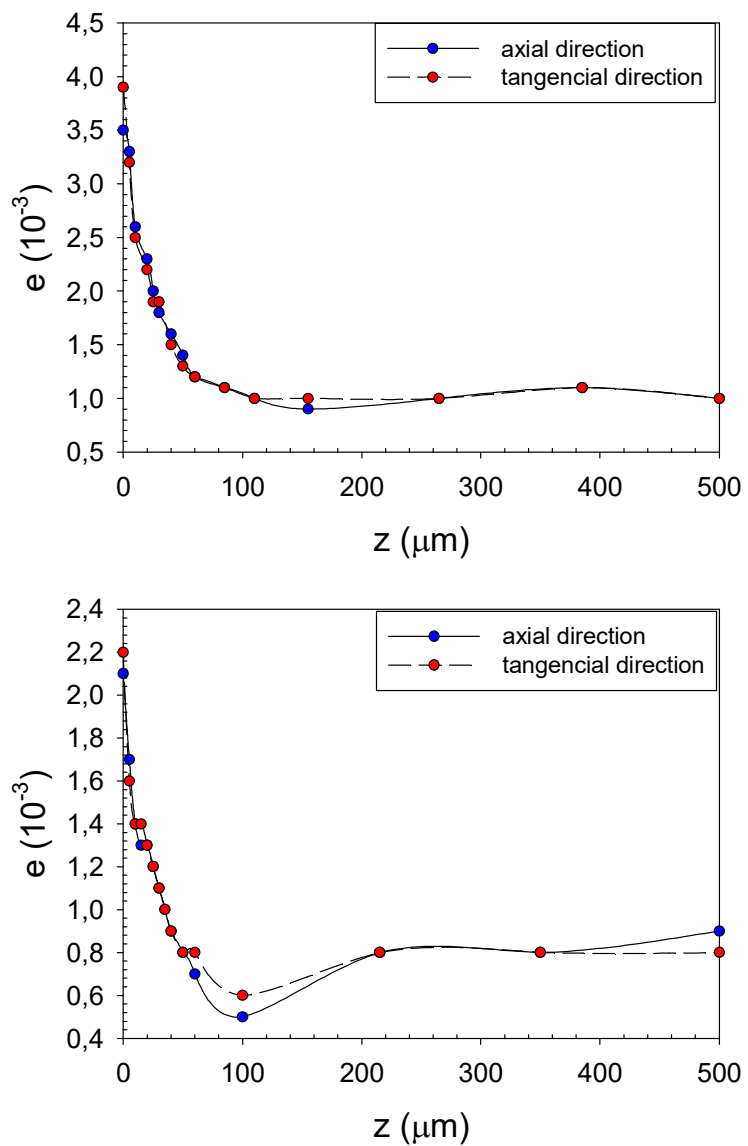

Surface Integrity after Turning a Duplex Stainless Steel with Respect to Tool Geometry
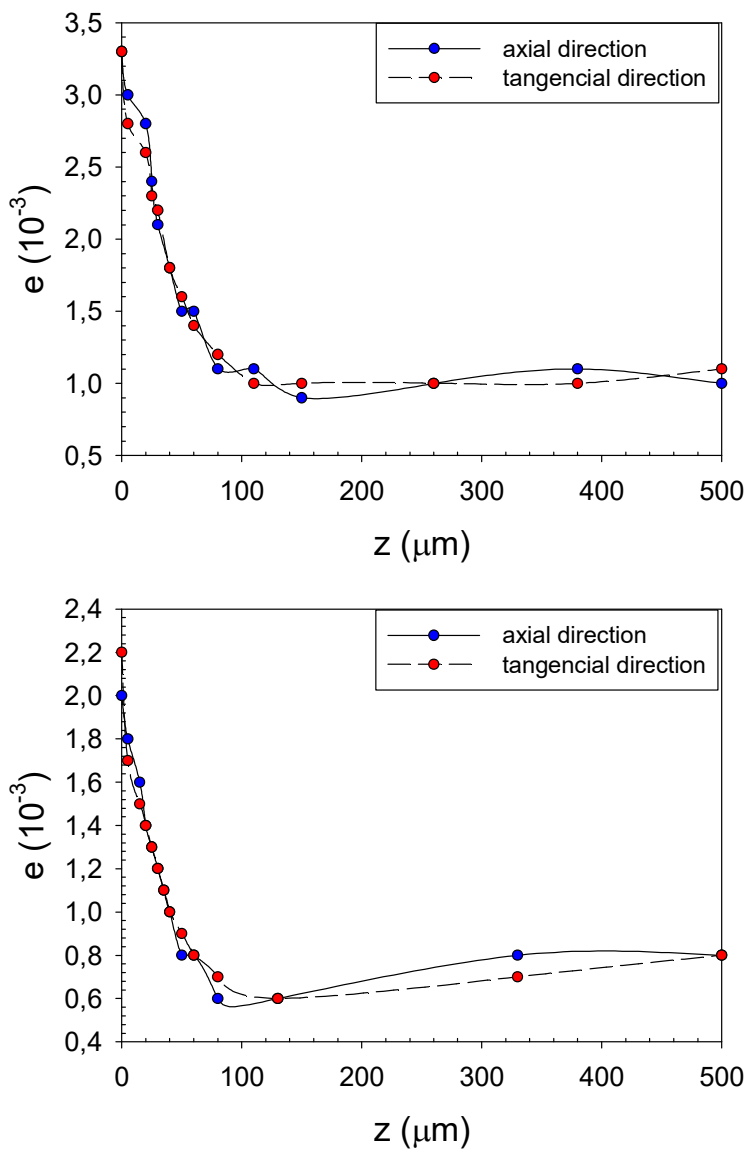

Fig. 6 Profiles of microdeformation $e$ of austenite (top) and ferrite (bottom) phase, rake angles of $-6^{\circ}$ (left) and $+12^{\circ}$ (right)

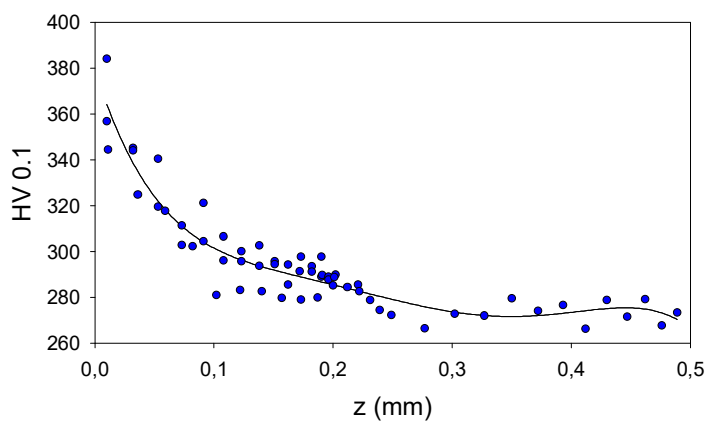

a) rake angle of $-6^{\circ}$

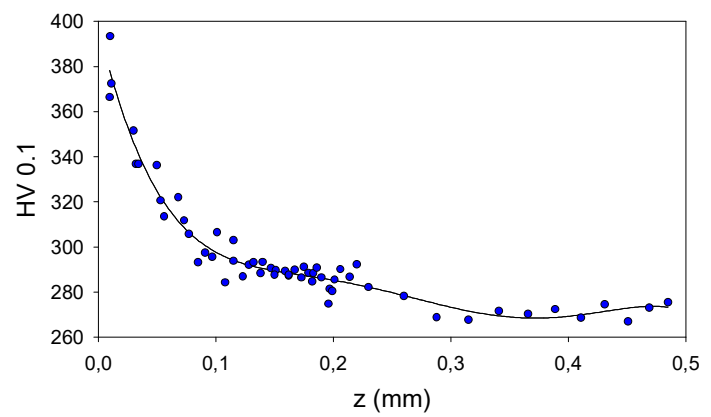

c) rake angle of $+7^{\circ}$

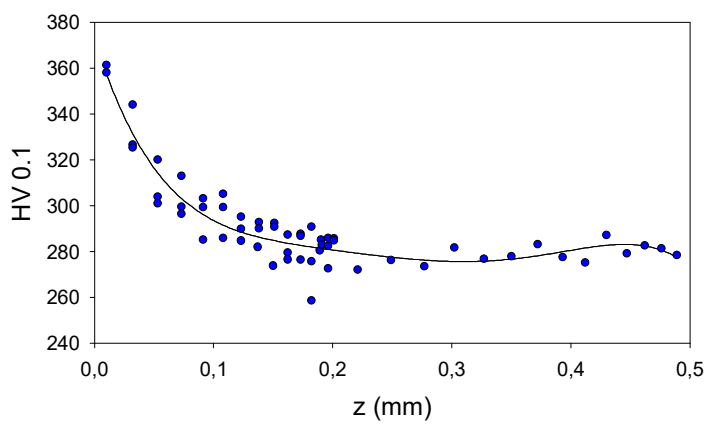

b) rake angle of $-2^{\circ}$

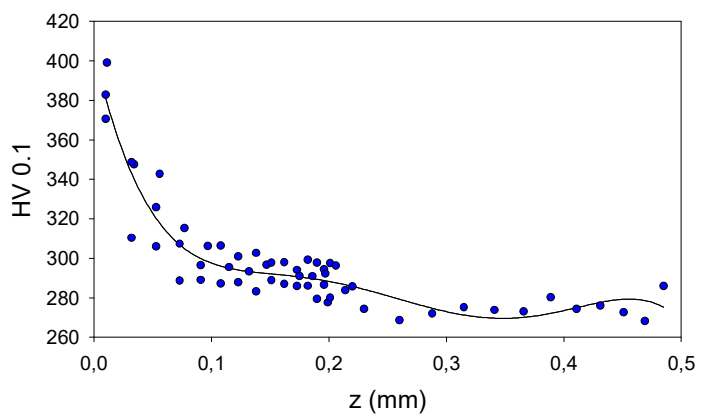

d) rake angle of $+12^{\circ}$

Fig. 7 Microhardness depth profiles 
Surface Integrity after Turning a Duplex

Stainless Steel with Respect to Tool Geometry
J. Čapek, K. Kolařík, M. Neslušan, Z. Pitrmuc,

L. Beránek, K. Trojan, J. Němeček, N. Ganev, J. Kyncl, P. Mikeš

\subsection{Strain-induced martensite determination and MBN measurements}

Fig. 8 shows micrographs of the machined surface in which the ferrite phase appears dark whereas the austenite phase is light. This figure also clearly shows that the turning process initiates the strain-martensite transformation, which appears blue in the near surface region. Fig. 8 also shows that an increase in the rake angle results in a lower volume of the strain-induced martensite. Moreover, the surfaces produced with the inserts at a negative rake angle also exhibit a thin austenite layer in the near surface region. The tool rake geometry affects mainly the chip separation process. However, the processes ahead the cutting edge remarkably contribute to energy consumption (expressed for instance in cutting force components) and the corresponding temperature in the cutting zone. Therefore, the stress and temperature distribution and the corresponding heat dissipation affect also the machined surface. As it was mentioned above, a decrease in the rake angle contributes to a higher consumption of energy in the cutting process, which energy is almost exclusively transformed to heat. Therefore, the higher volume of the strain-induced martensite in the case of negative rake angles results from more intensive severe plastic deformation at elevated temperatures in the tool flank - machined surface interface.

Fig. 9 illustrates the evolution of the $\mathrm{MBN}$ versus rake angle. It is worth mentioning that the evolution of the MBN along the rake angle strongly correlates with the evolution of RS versus rake angle of the ferrite phase since the austenite phase does not contribute to the MBN as a non-ferromagnetic phase. Fig. 9 clearly demonstrates that the axial direction is not sensitive against the transformation initiated in the machined surface whereas a higher MBN in the tangential direction can be found for the rake angles of $+12^{\circ}$ and $-6^{\circ}$. A comparison of Fig. 9 and Fig. $1 \mathrm{~b}$ shows that the RS of the ferrite phase strongly correlates with the MBN (see Fig. 10). However, it should be also mentioned that the MBN is usually driven by a synergistic effect of RS and microstructure. Fig. 11 illustrates that the shape of the MBN envelopes is modified (comparing bulk and machined surfaces). The bulk structure emits a remarkable single peak at the position of $0.5 \mathrm{kA} \cdot \mathrm{m}^{-1}$. On the other hand, all machined surfaces exhibit a decreased main peak originating from deeper untouched regions and higher values of MBN envelopes for a higher magnetic field in the range approx. from 1 to $5 \mathrm{kA} . \mathrm{m}^{-1}$ (see Fig. 11). It is assumed that higher values of the $\mathrm{MBN}$ envelope in this range of magnetic fields result from the transformation of the original ferrite-austenite matrix to the straininduced martensite (as a ferromagnetic phase).

It should be mentioned that the strain-induced martensite is a phase produced by a synergistic effect of severe plastic deformation at an elevated temperature, thus containing a higher dislocation density and a higher mechanical hardness (it can be proved by a higher microhardness in the subsurface regions as it is depicted in Fig. 7 - microhardness of the near surface region as the blue region in Fig. 8 cannot be directly measured by the use of this technique due to its low thickness). Higher mechanical hardness of a body usually corresponds with its higher magnetic hardness. Therefore, the presence of the strain-induced martensite can be detected in the region of higher magnetic fields, see Fig. 11. Fig. 11 also shows that the profile of the MBN envelopes (especially in the range of magnetic fields 1$5 \mathrm{kA} \cdot \mathrm{m}^{-1}$ ) corresponds with the MBN values in the tangential direction indicated in Fig. 9.

The machined surface after turning represents usually a preferentially oriented matrix in the direction of the cutting speed (tangential direction) at the expense of the perpendicular feed direction (axial direction). Therefore, MBN values and the corresponding MBN envelopes exhibit poor sensitivity against transformation initiated by turning, see Fig. 9 and Fig. 12. In comparison to the bulk MBN emission (Fig. 12) the surface strain hardening decreases the height of the MBN peaks of the machined surface and shifts them gently to the higher magnetic field. 
J. Čapek, K. Kolařík, M. Neslušan, Z. Pitrmuc, L. Beránek, K. Trojan, J. Němeček, N. Ganev, J. Kyncl, P. Mikeš
Surface Integrity after Turning a Duplex Stainless Steel with Respect to Tool Geometry

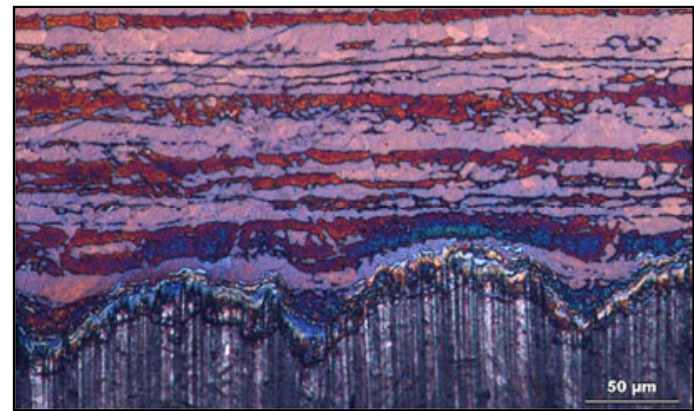

a) rake angle of $-6^{\circ}$

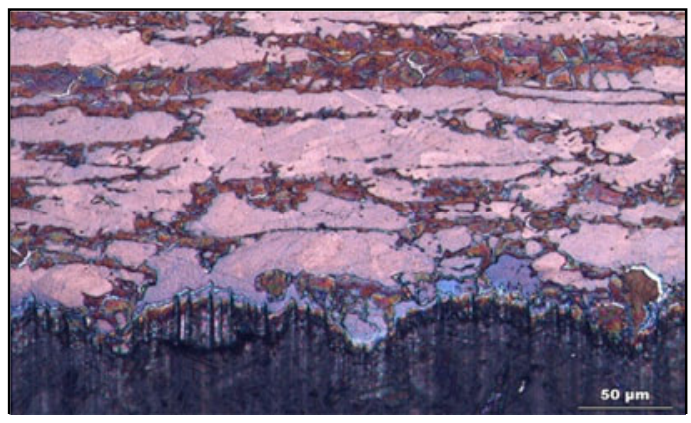

c) rake angle of $+7^{\circ}$

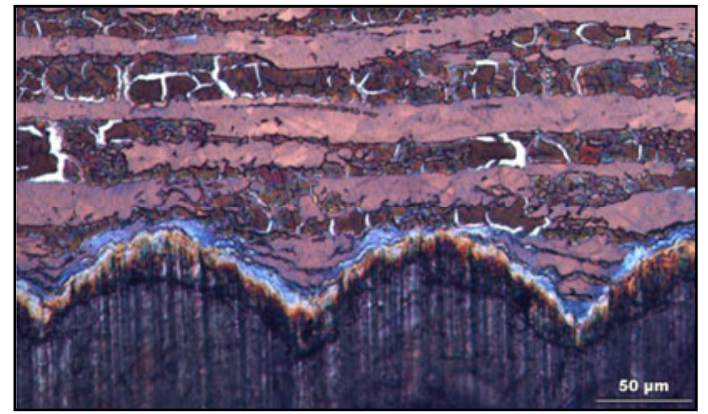

b) rake angle of $-2^{\circ}$

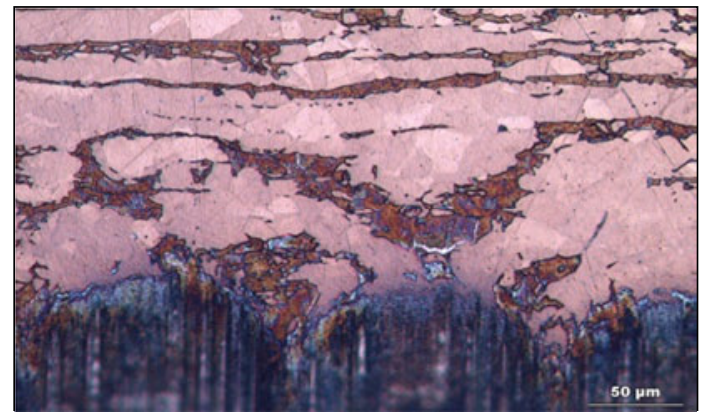

d) rake angle of $+12^{\circ}$

Fig. 8 Optical microscopy images of machined samples

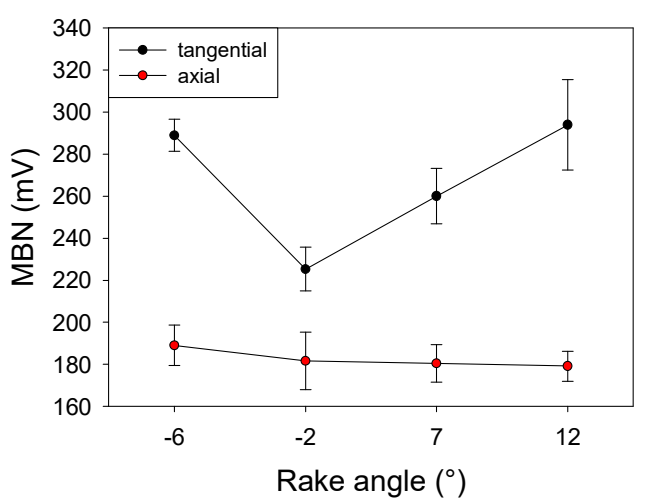

Fig. $9 \mathrm{MBN}$ versus rake angle

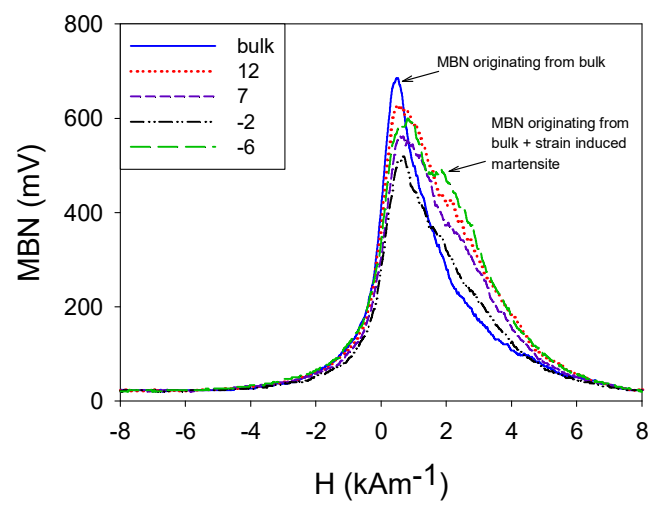

Fig. 11 Envelopes of MBN in tangential direction

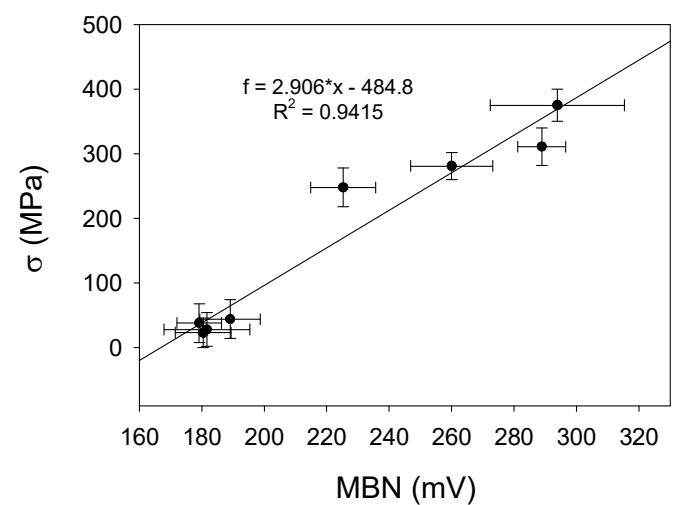

Fig. $10 \mathrm{MBN}$ versus $\mathrm{RS}$, correlation coefficient 0.97

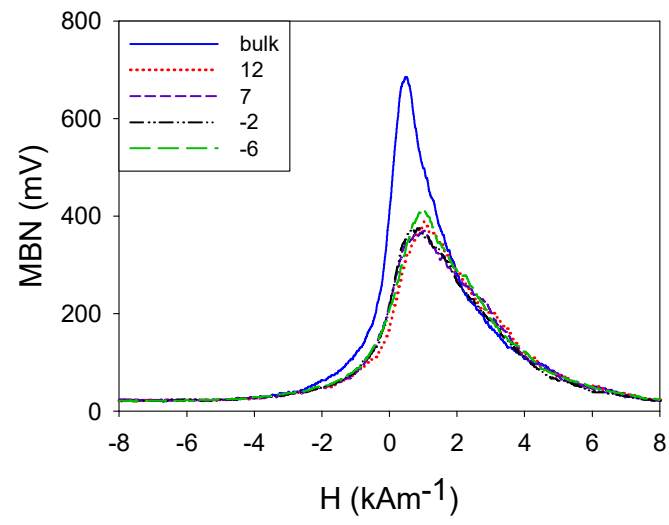

Fig. 12 Envelopes of MBN in axial direction 
The last aspect of the MBN evolution against the rake angle with respect to the microstructure transformations should be discussed. One might expect, that the trend MBN versus rake angle (Fig. 9) should be increasing due to an increase in the volume of the straininduced martensite. However, as it was mentioned above, the negative rake angles also produce a thin austenite layer, except for the strain-induced martensite. The conventional XRD technique using the Bragg-Brentano geometry is not capable of distinguishing among samples produced with inserts at a variable rake angle and clearly indicate changes of the ferrite/austenite phase ratios since the thickness of the near surface region altered by the cutting process is much lower than the XRD penetration depth. That being so, the information obtained from the thin affected (blue) layer is shadowed by the contribution of deeper layers less affected within the XRD penetration depth. For this reason, the GID XRD technique was employed in which the average penetration depth is only $0.3-0.5 \mu \mathrm{m}$. Fig. 13 illustrates the evolution of the ferrite volume in comparison with the rake angle. It can be reported that the volume of ferrite of all samples is much higher than that of the bulk. This volume is $59.2 \%$ in the case of the rake angle of $+12^{\circ}$ and there is an increase of $67.7 \%$ in the case of the rake angle of $+7^{\circ}$ followed by certain decrease in the case of the negative rake angles. Fig. 8 indicates that the volume strain-induced martensite increases along with the decreasing rake angle. However, the negative rake angles also produce a thin near surface austenite layer. Therefore, the indicated decreasing volume of ferrite in the case of negative rake angles is driven by the compensation effect of the initiated secondary austenite.

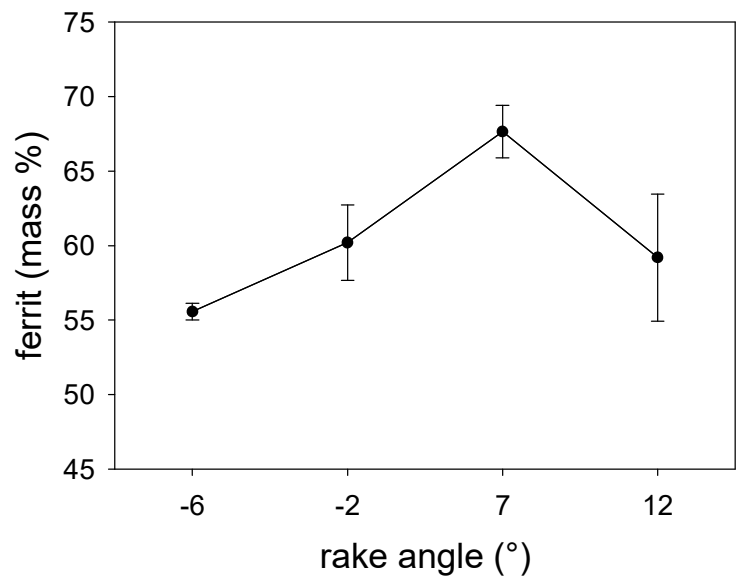

Fig. 13 Volume of ferrite in comparison with rake angle, bulk ferrite volume 40.9 mass \%

\section{Conclusion}

The present study shows that inserts at different rake angles produce a machined surface of variable surface integrity expressed in many terms. The rake angle affects mainly RSs in the cutting direction and different RSs can be found for the ferrite and the austenite phase. RSs determined by the hole-drilling method are approx. the average of the RSs determined by the XRD of the ferrite and the austenite phase, separately. The differences in the crystallite size and microdeformation between the ferrite and the austenite phase indicate more developed processes of plastic deformation of the austenite phase due to more variable slip systems. The intensity of the strain-induced microstructure transformation decreases along with an increase in the rake angle (Fig. 13). The MBN and the corresponding MBN envelopes are sensitive to both the RS and the microstructure. 
It is well known that resistance to fatigue (especially when resistance to corrosion or/and abrasion is superimposed) of a duplex stainless steel is driven by the boundary between phases. Negative rake angles initiate not only the strain-induced martensite but also the straininduced austenite phase, which in turn contributes to higher microdeformation on the phases boundaries. The strain-induced alterations in the near surface region initiated by the turning process are less developed in the case of positive rake angles. However, a higher RS in the case of the rake angle of $+12^{\circ}$ for the ferrite phase (see Fig. 1b) favours an insert to be applied for turning cycles at the rake angle of $+7^{\circ}$.

It was found that the tangential direction of the MBN measurement is more sensitive to the alterations of the surface after turning than the axial direction. The MBN emission originated from the strain-induced martensite affects the profile of the MBN envelope especially at a higher magnetic field.

\section{Acknowledgements}

Authors acknowledge the support of the Grant Agency of the Czech Technical University in Prague, grant No. SGS16/245/OHK4/3T/14 and the Czech Science Foundation, grant No. 1436566G. The research has been partially supported by the project CZ.02.1.01/0.0/0.0/16 019/0000778 "Center for advanced applied science" within the Operational Program Research, Development and Education supervised by the Ministry of Education, Youth and Sports of the Czech Republic and the ESIF, EU Operational Programme Research, Development and Education, and the Center of Advanced Aerospace Technology (CZ.02.1.01/0.0/0.0/16_019/0000826), Faculty of Mechanical Engineering, Czech Technical University in Prague. This study was supported by the University Science Park of the University of Zilina (ITMS: 26220220184) and by the Ministry of Education Youth and Sports of the Czech Republic 8X17013.

\section{REFERENCES}

[1] Dakhlaoui, R.; Braham, C.; Baczmański, A. Mechanical properties of phases in austeno-ferritic duplex stainless steel — surface stresses studied by X-ray diffraction, Materials Science and Engineering: A 2007, 444 (1), 6-17. https://doi.org/10.1016/j.msea.2006.06.074

[2] Lillbacka, R.; Chai, G.; Ekh, M.; Liu, P.; Johnson, E.; Runesson, K. Cyclic stress-strain behavior and load sharing in duplex stainless steels: Aspects of modeling and experiments, Acta Materialia 2007, 55 (16), 5359-5368. https://doi.org/10.1016/j.actamat.2007.05.056

[3] El Bartali, A.; Evrard, P.; Aubin, V.; Herenú, S.; Alvarez-Armas, I.; Armas, A. F.; Degallaix-Moreuil, S. Strain heterogeneities between phases in a duplex stainless steel. Comparison between measures and simulation, Procedia Engineering 2010, 2 (1), 2229-2237. https://doi.org/10.1016/j.proeng.2010.03.239

[4] Mateo, A.; Llanes, L.; Iturgoyen, L.; Anglada, M. Cyclic stress-strain response and dislocation substructure evolution of a ferrite-austenite stainless steel, Acta materialia 1996, 44 (3), 1143-1153. https://doi.org/10.1016/1359-6454(95)00197-2

[5] Polák, J.; Petrenec, M.; Kruml, T. Cyclic plastic response and fatigue life in superduplex 2507 stainless steel, International Journal of Fatigue 2010, 32 (2), 279-287. https://doi.org/10.1016/j.ijfatigue.2009.06.014

[6] Leppert, T.; Peng, R. L. Residual stresses in surface layer after dry and MQL turning of AISI 316L steel, Production Engineering 2012, 6 (4-5), 367-374. https://doi.org/10.1007/s11740-012-0389-3

[7] Haušild, P.; Kolařík, K.; Karlík, M. Characterization of strain-induced martensitic transformation in A301 stainless steel by Barkhausen noise measurement, Materials \& Design 2013, 44, 548-554. https://doi.org/10.1016/j.matdes.2012.08.058

[8] Krolczyk, G.; Legutko, S. Investigations into surface integrity in the turning process of duplex stainless steel, Transactions of FAMENA 2014, 38 (2), 77-82. 
Surface Integrity after Turning a Duplex

Stainless Steel with Respect to Tool Geometry
J. Čapek, K. Kolařík, M. Neslušan, Z. Pitrmuc,

L. Beránek, K. Trojan, J. Němeček, N. Ganev,

[9] Park, H. S.; Nguyen, T. T.; Kim, J. C. An energy efficient turning process for hardened material with multi-criteria optimization, Transactions of FAMENA 2016, 40 (1), 1-14.

[10] Schwarz, K. T.; Kormout, K. S.; Pippan, R.; Hohenwarter, A. Impact of severe plastic deformation on microstructure and fracture toughness evolution of a duplex-steel, Materials Science and Engineering: $A$ 2017, 703, 173-179. https://doi.org/10.1016/j.msea.2017.07.062

[11] Čapek, J.; Kolařík, K.; Beránek, L.; Molotovník, A.; Ganev, N. Residual stress analysis into each phase of turning duplex steel and their influence on service life of rotary and dynamically loaded components, In: The 5th Student Scientific Conference on Solid State Physics 2015, 11-15.

[12] Moverare, J. J.; Odén, M. Deformation behaviour of a prestrained duplex stainless steel, Materials Science and Engineering: A 2002, 337 (1-2), 25-38. https://doi.org/10.1016/S0921-5093(02)00022-9

[13] Kolařík, K.; Pala, Z.; Ganev, N.; Fojtik, F. Combining xrd with hole-drilling method in residual stress gradient analysis of laser hardened c45 steel, Advanced Materials Research 2014, 996, $277-282$. https://doi.org/ 10.4028/www.scientific.net/AMR.996.277

[14] Rietveld, H. A profile refinement method for nuclear and magnetic structures, Journal of applied Crystallography 1969, 2 (2), 65-71.

[15] Neslušan, M.; Majerík, J.; Kejzlar, P.; Čilliková, M.; Mičietová, A. Barkhausen Noise Emission in Hard Milled Surfaces of Steel C55, Transactions of FAMENA 2016, 39 (4), 55-64.

[16] Č́žek, J.; Neslušan, M.; Čilliková, M.; Mičietová, A.; Melikhova, O. Modification of steel surfaces induced by turning: non-destructive characterization using Barkhausen noise and positron annihilation, Journal of Physics D: Applied Physics 2014, 47 (44), 445301.

[17] Neslušan, M.; Č́žžek, J.; Kolař́ík, K.; Minárik, P.; Čilliková, M.; Melikhova, O. Monitoring of grinding burn via Barkhausen noise emission in case-hardened steel in large-bearing production, Journal of Materials Processing Technology 2017, 240, 104-117. https://doi.org/10.1016/j.jmatprotec.2016.09.015

[18] Lindgren, M.; Santa-aho, S.; Bjork, T.; Vippola, M. Barkhausen noise response of fatigue tested super duplex stainless steel, In: The 12th International Conference on Barkhausen Noise and Micromagnetic Testing 2018, 159-169.

[19] Normando, P. G.; Moura, E. P.; Souza, J. A.; Tavares, S. S.; Padovese, L. R. Ultrasound, eddy current and magnetic Barkhausen noise as tools for sigma phase detection on a UNS S31803 duplex stainless steel, Materials Science and Engineering: A 2010, 527 (12), 2886-2891. https://doi.org/10.1016/j.msea.2010.01.017

[20] Mészáros, I.; Szabo, P. J. Complex magnetic and microstructural investigation of duplex stainless steel, NDT \& E International 2005, 38 (7), 517-521. https://doi.org/10.1016/j.ndteint.2004.12.007

[21] Lindgren, M.; Lepistö, T. Relation between residual stress and Barkhausen noise in a duplex steel, NDT \& E International 2003, 36 (5), 279-288. https://doi.org/10.1016/S0963-8695(03)00002-1

[22] Welzel, U.; Ligot, J.; Lamparter, P.; Vermeulen, A. C.; Mittemeijer, E. J. Stress analysis of polycrystalline thin films and surface regions by X-ray diffraction, Journal of Applied Crystallography 2005, 38 (1), 1-29. https://doi.org/10.1107/S0021889804029516

[23] Neckář, F.; Kvasnička, I. Vybrané state z úberu materiálu, České vysoké učení technické, 1991.

[24] Dahlman, P.; Gunnberg, F.; Jacobson, M. The influence of rake angle, cutting feed and cutting depth on residual stresses in hard turning, Journal of Materials Processing Technology 2004, 147 (2), 181-184. https://doi.org/10.1016/j.jmatprotec.2003.12.014 
J. Čapek, K. Kolařík, M. Neslušan, Z. Pitrmuc, L. Beránek, K. Trojan, J. Němeček, N. Ganev, J. Kyncl, P. Mikeš
Surface Integrity after Turning a Duplex Stainless Steel with Respect to Tool Geometry
Submitted: $\quad 20.3 .2018$

Accepted: $\quad 11.10 .2018$
Jiř́ Čapek

Kamil Kolařík

Karel Trojan

Jakub Němeček

Nikolaj Ganev

Department of Solid State Engineering,

Faculty of Nuclear Sciences and Physical

Engineering, Czech Technical University in Prague, Břehová 7, Prague, Czech

Republic

Miroslav Neslušan

Faculty of Mechanical Engineering,

University of Žilina, Univerzitná 8215/1,

Žilina, Slovak Republic

Zdeněk Pitrmuc

Jiří Kyncl

Department of Machining, Process

Planning and Metrology, Faculty of

Mechanical Engineering, Czech Technical

University in Prague, Technická 4, Prague,

Czech Republic

Libor Beránek

Petr Mikeš

Department of Instrumentation and

Control Engineering, Faculty of

Mechanical Engineering, Center of

Advanced Aerospace Technology, Czech

Technical University in Prague, Technicka

4, Prague, Czech Republic 